\title{
REFLEXÕES SOBRE POSSIBILIDADES PARA O DESENVOLVIMEN- TO DA CIDADANIA POR MEIO DA EDUCAÇÃO FÍSICA NO ENSINO MÉDIO'
}

\author{
Daniel Teixeira Maldonado \\ Instituto Federal de Educação, Ciência e Tecnologia de São Paulo, São Paulo, São Paulo, Brasil \\ Valdilene Aline Nogueira \\ Universidade de Guarulhos, Guarulhos, São Paulo, Brasil \\ Sheila Aparecida Pereira dos Santos Silva \\ Universidade São Judas Tadeu, São Paulo, São Paulo, Brasil
}

\begin{abstract}
Resumo
O objetivo desse trabalho foi refletir sobre a contribuição da Educação Física (EF) na formação da cidadania dos alunos que frequentam o Ensino Médio (EM) e, ao mesmo tempo, buscar resposta(s) para a pergunta: "Existe espaço para esse componente curricular no EM após a promulgação da Medida Provisória (MP) n 746/2016?”. Utilizamos como base para a reflexão duas experiências pedagógicas realizadas por professores de EF em escolas com características diferentes, mas que buscam a formação do pensamento crítico dos estudantes sobre as manifestações da cultura corporal. Concluímos que existe espaço para a EF no EM com o papel de formar pessoas conscientes da importância de práticas saudáveis, da adoção de um estilo de vida ativo e para a consciência cidadã e democrática.
\end{abstract}

Palavras-chave: Educação Física Escolar. Ensino Médio. Cidadania.

\section{REFLECTIONS ABOUT POSSIBILITIES FOR THE DEVELOPMENT OF CITI- ZENSHIP BY PHYSICAL EDUCATION IN HIGH SCHOLL}

\begin{abstract}
The goal of this study was to reflect about the contribution of Physical Education (PE) in the formation of citizenship of pupils attending high school (HS) and, at the same time, seek answers to the question: "Is there space for PE in this curriculum after the promulgation of the Provisional Measure ${ }^{\circ}$. 746/2016?". We used two pedagogical experiences conducted by teachers of PE in schools with different characteristics, but which have in common the relentless pursuit by the formation of critical thinking about the manifestations of the body culture. We conclude that there is space for the PE in the role of forming people aware of the importance of healthy practices and to the awareness among citizens on the basis of democratic values.
\end{abstract}

Keywords: Physical Education Classes. High school. Citizenship.

\footnotetext{
${ }^{1} \mathrm{O}$ presente trabalho não contou com apoio financeiro de nenhuma natureza para a sua realização.
} 


\title{
REFLEXIONES SOBRE POSIBILIDADES DEL DESARROLLO DE LA CIUDA- DANÍA POR MEIO DE LA EDUCACIÓN FÍSICA EN LA ESCUELA SECUNDARIA
}

\author{
Resumen \\ El objetivo de este estudio fue reflexionar sobre la contribución de la Educación Física (EF) \\ en la formación de la ciudadanía de los estudiantes que asisten a la escuela secundaria (ES) \\ mientras buscamos respuesta(s) a la pregunta: "Hay lugar para esa asignatura en el plan de \\ estudios en la ES después de la promulgación de la Medida Provisional. n ${ }^{\circ}$ 746/2016?". \\ Hemos utilizado como base para la reflexión dos experimentos pedagógicos realizados por \\ profesores de EF en dos escuelas diferentes, pero tienen en común la formación del pensa- \\ miento crítico de los estudiantes acerca de la cultura corporal. Hay espacio para EF en la ES \\ con la función de formar personas conscientes de la importancia de las prácticas saludables y \\ para la conciencia ciudadana.
}

Palabras clave: Educación Física Escolar. Escuela Secundaria. Ciudadanía.

\section{Introdução}

O currículo é uma criação humana e, por conta disso, traz no seio da sua construção aspectos históricos, culturais, políticos e econômicos. Portanto, a escolha das disciplinas que compõem a grade curricular das escolas públicas brasileiras sempre foi um campo de disputa entre aqueles que elaboram as políticas educacionais e os profissionais que lecionam em contextos educacionais formais na esfera municipal, estadual, federal ou particular.

A EF se estabeleceu como disciplina a ser ensinada na escola no século XIX. Desse momento histórico até os dias atuais, muitos embates ocorreram, diversas perspectivas pedagógicas foram criadas a partir de diferentes visões de mundo, a EF se estabeleceu nas legislações federais como componente curricular obrigatório em todos os segmentos da Educação Básica e também esteve presente em documentos curriculares oficiais (CORREIA, 2011).

Correia (2011), no entanto, alertava que, apesar dos dispositivos legais e formais garantirem a EF em todos os ciclos de escolarização da Educação Básica (legalidade), existia a necessidade de lutar pela legitimidade do seu papel educativo, principalmente no EM.

Todas as vezes em que ouvimos ou lemos uma defesa da manutenção da EF como componente curricular por meio de imposições legais, fica mais claro que a EF não conseguiu, até o momento, conquistar a tão desejada legitimidade social.

Se houvesse uma representação social que valorizasse a EF como uma área de conhecimento e um componente curricular da Educação Básica que fornece uma contribuição indispensável à formação da população brasileira, não teríamos necessidade de leis que obrigassem a sua inclusão nos currículos escolares, pois os próprios pais e educadores cuidariam desta inclusão sem precisar ficar na esteira e na dependência de textos legais e/ou das decisões de políticos que, vez ou outra, mostram total desconhecimento das potencialidades e das contribuições da EF para a vida das pessoas.

Mais uma vez, na história brasileira, a EF surge no cenário dos dispositivos legais, desta vez por ocasião das discussões que antecederam a publicação da MP $n^{\circ} 746 / 2016$, pois quando a iminente retirada da obrigatoriedade da EF no currículo escolar foi divulgada pela mídia, as primeiras reações dos professores de EF foram de surpresa, revolta, indignação, mobilização de alguns segmentos da profissão, sentimento de onipotência de outros. 
Em geral, os debates observados em diferentes veículos de comunicação, no interior das escolas, ou em conselhos representativos da profissão de EF mencionavam o "absurdo" que seria retirá-la do EM justamente no ano em que o Brasil sediou os Jogos Olímpicos.

Em meio a estas discussões, era possível observar que a EF possui legitimidade em alguns segmentos sociais se for capaz de identificar talentos esportivos, formar atletas, impedir a disseminação da obesidade entre os jovens, ocupar o tempo dos adolescentes mais pobres para que não se "entreguem" ao crime e às drogas.

Ao constatar os argumentos mencionados para sustentar a necessidade da presença da EF no processo educativo de crianças e adolescentes, a sensação que tínhamos era que o aspecto principal estava sendo abandonado, ou seja, uma visão integral das dimensões que compõem o ser humano e o trabalho integrado dos diferentes educadores e dos diferentes componentes de um currículo escolar. Da ausência desta perspectiva, decorria a sensação de que, há muitos anos, a EF possui belos discursos a respeito de sua contribuição para a formação integral das pessoas, mas, infelizmente, sem contar com práticas pedagógicas coerentes com esses ideários.

Nosso sentimento era de que muito se evoluiu na EF nas últimas décadas, no entanto, as gerações que ocupam cargos com poder de decisão sobre ações que podem impactar na vida da população brasileira e na educação das futuras gerações tiveram experiências durante as aulas de EF que resultaram em uma formação fragmentada, seletiva, autoritária, acrítica, ou seja, muito distante do que seria desejável para que a contribuição da EF na educação do cidadão brasileiro fosse legitimada em toda sua potencialidade.

Reflexos deste tipo de formação insuficiente e distorcida foram as dúvidas e afirmações constatadas nos debates midiáticos e nas argumentações de alguns órgãos de classe que validavam a EF na escola por razões, no mínimo, discutíveis. Esses reflexos também foram observados no comportamento dos legisladores, sem dúvida assessorados inclusive por educadores, ao pensarem na retirada desse componente curricular como disciplina obrigatória do EM como parte de sua reforma.

Na sociedade contemporânea, em que os jovens são cada vez mais bombardeados com informações superficiais sobre as manifestações da cultura corporal e a mídia impressa e televisiva evidencia a dificuldade de aprofundar temas especializados e importantes ligados às práticas corporais, a EF só será validada na escola se o seu docente adotar uma didática crítica, que privilegie a aprendizagem de temas relevantes para os estudantes e rompa com a política de mera fruição nas aulas (BOSSLE; BOSSLE; NEIRA, 2016).

Nesse sentido, a EF deve possibilitar a releitura e a apropriação crítica dos conhecimentos da cultura corporal, estimulando que o estudante vivencie, reflita e recrie sobre o maior leque possível de práticas corporais que são realizadas pelos seres humanos em diferentes partes do mundo. Dessa forma, os jovens poderão finalizar todas as etapas da Educação Básica tendo tido acesso ao conhecimento sistematizado pelos seres humanos sobre os esportes, as danças, as lutas, as ginásticas, os jogos e brincadeiras, tornando-se um cidadão que valoriza, reconhece, compreende e discute sobre as práticas corporais em sua vida adulta (GONZÁLEZ; FRAGA, 2012).

Nossa contribuição para o debate a respeito da busca da legitimidade da EF no processo educativo das pessoas, em defesa de um processo que tenha como base as múltiplas dimensões do ser humano e que é voltado para a construção da cidadania, será feito por meio de exemplos de práticas pedagógicas realizadas. Com esse intuito, apresentaremos duas experiências nas quais professores de EF do EM, em escolas com características muito diferentes, tematizaram práticas corporais tendo como objetivo estimular a criticidade e a reflexão dos estudantes com vistas à formação cidadã. 
A professora da escola 1 (P1) se embasou na Metodologia de Projetos para a construção de sua prática pedagógica, enquanto o professor da escola 2 (P2) obteve seu direcionamento didático nas Teorias Críticas da EF.

Embora esses docentes tenham atuado com fundamentações teóricas diferentes e em escolas que possuem contextos educacionais diversos, um importante aspecto existe em comum: a EF é considerada um componente curricular importante para estimular a formação da cidadania dos estudantes e, devido a isso, conquistou um espaço significativo no currículo escolar.

\section{O Contexto Da Escola 1}

A Cooperativa Educacional em que ocorreu a experiência pedagógica que será descrita foi fundada em agosto de 1992, buscando oferecer na cidade de Viçosa uma unidade educacional que propiciasse a melhoria da qualidade do ensino de $5^{\mathrm{a}}$ a $8^{\mathrm{a}}$ série e fosse capaz de permitir um modelo de escola em que houvesse mais participação dos pais.

Em 2008, priorizando o desenvolvimento da escola, foi realizada uma mudança em sua estrutura administrativa, passando de cooperativa de pais para cooperativa de profissionais da educação. A escola afirma trabalhar com uma pedagogia fundamentada em um modelo de educação que visa a formação de indivíduos capazes de criar, de transformar, de decidir, de criticar, de verificar, de se sensibilizar com as coisas do mundo e com pontos de vista e sentimentos do outro.

Para assegurar e consolidar a proposta pedagógica da escola por toda a Educação Básica implantou-se o EM no início de 2010. Atualmente, a Escola atende crianças de 02 a 17 anos de idade.

O planejamento participativo nessa escola nasce junto à ideia da Pedagogia de Projetos que embasa os seus documentos pedagógicos. A Pedagogia de Projetos se fundamenta nos ensinamentos de Dewey $(1959,1978,2002)$ e Kilpatrick (1974) e sugere a atuação do sujeito informado da essência de um conhecimento constituído por várias fontes que pode ser acessado por meio da inter-relação do aprendiz com o meio. Dewey e Kilpatrick são considerados autores clássicos na área da Educação, seus ensinamentos foram atualizados por Hernández e Ventura (1998) e serviram como base para a construção da proposta pedagógica dessa Cooperativa Educacional.

Neste tipo de proposta, o professor de EF, mesmo não sendo meio direto para aquisição de conhecimento sobre todos os conteúdos, uma vez que o ensino não é baseado na pura transmissão, constitui uma das várias fontes de conhecimento e é responsável por promover possibilidades de modificação/atualização das informações. Seu modo de ensinar, portanto, vai além do transmitir e passa pela experimentação das possibilidades que as práticas corporais oferecem.

Por meio da elaboração e participação ativa em trabalhos em grupos, entende-se que o fazer pedagógico é favorável ao envolvimento e responsabilidade no sentido de buscar atitudes baseadas na democracia e na participação (KILPATRICK, 1974).

A experiência realizada na escola 1 foi efetivada por P1, que atuou como professora de EF na Educação Infantil de 2009 a 2011 e, posteriormente, no Ensino Fundamental II e no EM até 2015.

As aulas de EF, nessa escola, são construídas de maneira entrelaçada aos problemas do cotidiano dos educandos, que são estimulados a pensar no significado que atribuem a elas. A elaboração dos planejamentos pretende ocorrer de maneira democrática. Os projetos escolhidos resultam do interesse e envolvimento dos educandos e educadores que, a partir da constituição de assembleias, dedicam-se a pesquisas, discussões e vivências dos temas da cultura corporal (NOGUEIRA, 2016). 
No início de 2015, as assembleias traçaram o desenho dos projetos coletivos, ou seja, aqueles que seriam desenvolvidos por toda a comunidade escolar e divididos entre os estudantes, mesmo pertencentes a classes diferentes, mas que se interessavam por assuntos comuns. Também foram definidos os projetos que seriam desenvolvidos durante as aulas específicas de cada disciplina.

Aqui trazemos um relato da construção e do desenvolvimento do planejamento da disciplina EF no ano de 2015 pela turma do $2^{\circ}$ ano do EM. Cabe lembrar que, em geral, os projetos são transdisciplinares, envolvem toda a escola, e aqui destacamos as contribuições da EF aos projetos.

\section{Ensinar Por Meio De Projetos Com Vistas Ao Desenvolvimento Do Estudante Em Múl- tiplas Dimensões}

Com o objetivo de traçar o planejamento do que ocorreria nas aulas e nas experiências promovidas pela $\mathrm{EF}$, professora e estudantes iniciaram pela investigação de práticas corporais a serem tematizadas nos projetos.

Essa pesquisa ocorreu na sala de informática da escola e continuou em casa, onde os estudantes entrevistaram amigos e parentes e selecionaram reportagens sobre assuntos que pudessem ser discutidos na disciplina. A professora também trouxe sugestões de assuntos e práticas e, juntos, organizaram uma pré-seleção dos conteúdos a serem desenvolvidos pela turma, com base em literatura da área selecionada anteriormente pela professora.

Nesta fase de planejamento, muitas dúvidas surgiram para a docente. Por exemplo: Como seria uma forma adequada de discutir a utilização de esteroides anabolizantes nas academias? Como discutir os padrões de beleza presentes na sociedade? Como colocar em discussão as razões pelas quais os estudantes vindos de outras escolas não participam das aulas de EF?

Nessa etapa foi muito fácil identificar as representações sociais que os estudantes possuíam a respeito das aulas de EF e alguns estereótipos ligados ao seu contexto. Alguns estudantes propuseram que os conteúdos deveriam se restringir aos esportes coletivos e que as aulas deveriam ter o caráter de treinamentos preparatórios para campeonatos. Dois estudantes propuseram usar o tempo da aula de EF para estudar para provas de outras disciplinas. Um estudante propôs que os meninos jogassem futsal e as meninas voleibol em todas as aulas. Diante da constatação da presença de ideias, preconceitos e tendenciosidades que, justamente, desejava superar, P1 viu que o caminho recomendado e fiel aos valores democráticos seria o diálogo sobre essas expectativas e sobre a função da EF na escola.

Promover uma educação democrática não significa que o professor é subjugado pelas ideias e desejos dos estudantes, mas que sabe agir e organizar a sua prática pedagógica como um adulto que possui extensa fundamentação teórico-prática, alguma sabedoria de vida, e que saiba trazer argumentos que mostrem aspectos positivos e negativos das propostas dos estudantes dentro de um quadro de referência que também deve ficar claro a todos.

Deixa de contribuir com o desenvolvimento dos educandos o professor que cede a pressões da maioria e se omite de argumentar, de analisar, de empreender discussões e debates entre pontos de vista diferentes e, com essa atitude, acaba por condenar os educandos a permanecerem onde estão sem nenhum desequilíbrio que poderia proporcionar-lhes alguma evolução.

Tendo em mente o respeito devido ao ponto de vista dos estudantes e a necessidade de evoluir no debate sobre as ideias presentes no grupo, P1 organizou, durante o mês de fevereiro, um quadro (Quadro 1) com as sugestões aceitas nas assembleias e, com base nele, os estudantes e a educadora sugeriram as atividades que pretendiam realizar durante o decorrer do ano. Um dos exemplos foi a decisão coletiva de desenvolver um projeto de voleibol próximo 
ao Campeonato Mundial de Clubes, que aconteceria em Betim - MG. Neste projeto, além de estudar sobre o voleibol, também seriam arrecadados fundos para organizar uma excursão para assistir à final desse campeonato.

Quadro 1 - Temas e Expectativas da turma do $2^{\circ}$ ano do Ensino Médio em 2015

\begin{tabular}{|c|c|}
\hline TEMAS & EXPECTATIVAS \\
\hline $\begin{array}{l}\text { Ensinar o que } \\
\text { gostamos }\end{array}$ & $\begin{array}{l}\text { Organização de oficinas para a Educação Infantil com alguns temas que } \\
\text { estudamos nos anos anteriores: Grandes e Pequenos Jogos, Maculelê e } \\
\text { Congado. }\end{array}$ \\
\hline Semana Radical & $\begin{array}{l}\text { Vivência e estudo de diversas possibilidades de manifestações culturais } \\
\text { radicais ou de aventura, tais como: montanhismo, rapel, skate, patins, bike e } \\
\text { parkour. }\end{array}$ \\
\hline Ginástica em Ação & $\begin{array}{c}\text { Vivência das diversas possibilidades gímnicas: ginástica olímpica, ginástica } \\
\text { aeróbica, ginástica geral, trampolim e ginástica artística, excursão ao } \\
\text { Pavilhão de Ginástica da UFV. }\end{array}$ \\
\hline $\begin{array}{l}\text { O sexismo no } \\
\text { esporte: } \mathrm{O} \text { que } \\
\text { podemos mudar? }\end{array}$ & $\begin{array}{l}\text { Torneios e seminários; elaborar um torneio de futebol em campo sintético } \\
\text { pensando em alternativas para a participação feminina. }\end{array}$ \\
\hline $\begin{array}{l}\text { O Judô e outras } \\
\text { lutas na escola }\end{array}$ & $\begin{array}{c}\text { Quais são os limites da expressividade dos corpos no que se refere à } \\
\text { masculinidade e feminilidade? Por que nunca tivemos professora de lutas na } \\
\text { escola? Pesquisa, visita à academia de lutas, vivência da luta, pedir ajuda ao } \\
\text { professor de capoeira do Ensino Fundamental I. }\end{array}$ \\
\hline $\begin{array}{l}\text { Gincana de } \\
\text { Integração }\end{array}$ & Gincana com estafetas e provas variadas. Atividades tradicionais de gincana. \\
\hline $\begin{array}{l}\text { Musculação, } \\
\text { Suplementos e } \\
\text { Esteroides } \\
\text { Anabolizantes: } \\
\text { tenho corpo ou } \\
\text { tenho shape? }\end{array}$ & $\begin{array}{l}\text { Tematizar a musculação; discutir sobre o uso de anabolizantes; visitar } \\
\text { academias; organizar uma palestra sobre o tema para todo o EM; discutir os } \\
\text { padrões de beleza e o mundo fitness. }\end{array}$ \\
\hline $\begin{array}{l}\text { As Metas do } \\
\text { Milenio para um } \\
\text { mundo melhor }\end{array}$ & $\begin{array}{l}\text { Trabalhar dentro do projeto interdisciplinar a desigualdade social, a fome e a } \\
\text { pobreza; analisar os fenômenos esportivos e as diferentes culturas no mundo; } \\
\text { experimentar danças, comidas e jogos de países elencados pela UNESCO } \\
\text { como mais carentes de políticas públicas afirmativas. }\end{array}$ \\
\hline $\begin{array}{l}\text { Nosso esporte } \\
\text { preferido: } \\
\text { Vivenciando o } \\
\text { voleibol }\end{array}$ & $\begin{array}{c}\text { Aprender o rodizio } 5 \times 1 \text {; analisar a hegemonia brasileira no esporte nas } \\
\text { últimas competições; organizar jogos com turmas dos outros anos; pensar } \\
\text { estratégias para angariar dinheiro e propor uma excursão para } \\
\text { acompanharmos um jogo de Voleibol no Campeonato Mundial de Clubes em } \\
\text { Betim-MG. }\end{array}$ \\
\hline $\begin{array}{l}\text { Dia da Consciência } \\
\text { Corporal }\end{array}$ & $\begin{array}{c}\text { Como as questões da qualidade de vida se dão no cotidiano das famílias? } \\
\text { Como o lazer está condicionado? A lógica de tempo, cidadania, escola e } \\
\text { saúde. Palestras, vivências e debates. }\end{array}$ \\
\hline $\begin{array}{l}\text { Festa Junina: Agua } \\
\text { mole em pedra } \\
\text { dura, quando tem é } \\
\text { só fartura }\end{array}$ & $\begin{array}{c}\text { Escolher as músicas; pensar nas coreografias, nos jogos e brincadeiras da } \\
\text { festa; trabalhar na venda e preparação das comidas; tematizar o racionamento } \\
\text { de água e seleção dos recursos naturais na montagem de painéis e na } \\
\text { coreografia da turma. }\end{array}$ \\
\hline
\end{tabular}

Fonte: Elaborado pelo autor, 2015.

O quadro ficou exposto durante todo o ano na sala da turma e, na medida em que novas ideias sobre os projetos surgiam, eram discutidas durante as duas aulas semanais.

Além do quadro, mantinha-se um painel de notícias. A ideia era incentivar a organização dos trabalhos com diferentes mídias como filmes, documentários, reportagens especiais, com o objetivo de estabelecer conexões com o planejamento de EF e favorecer a interatividade. A estimulação a esse tipo de pesquisa visou um aprofundamento temático e gerou possibilidades de o educando se posicionar de maneira ativa diante do conhecimento a ser veiculado.

Após a montagem do Quadro 1, elaborou-se um cronograma e foram iniciados os projetos. Considerando que existem várias possibilidades de implementação do trabalho por projetos, na organização da EF, em especial, partiu-se de uma sistematização estabelecida na 
escola com base nos ensinamentos de Hernández e Ventura (1998), adaptada para a especificidade da disciplina.

Esses autores sugerem que se deve passar por algumas fases para o desenvolvimento de um projeto. No planejamento, as etapas foram:

1. Partir de um tema ou de uma problematização acerca da cultura corporal;

2. Iniciar um processo de pesquisa sobre esse tema;

3. Buscar e selecionar fontes de informação (livros, revistas, entrevistas, reportagens, pesquisas na internet, etc.);

4. Estabelecer critérios de organização e interpretação das fontes de informação;

5. Criar uma lista de objetivos de aprendizagem sobre o tema;

6. Vivenciar as práticas corporais que permeiam o tema de pesquisa em suas mais diversas possibilidades;

7. Montar um portfólio com as ações realizadas e com os conhecimentos aprendidos;

8. Conectar-se a um novo tema ou problema para futuros estudos;

9. Organizar o processo de finalização do projeto a partir do conhecimento vivido;

10. Elaborar uma mostra, festival, competição ou festa, de modo a transformar o conhecimento em algo palpável e que possa ser compartilhado com a comunidade escolar.

Além dessa sistematização, decidiu-se que a avaliação do aprendizado aconteceria durante o andamento das atividades, por meio de textos, trabalhos e seminários elaborados, participação no processo, e culminaria com a organização de um evento ou mostra para compartilhar com a comunidade escolar aquilo que havia sido estudado e construído. Decidiu-se também que o encerramento de cada projeto só aconteceria quando fosse decidido pelo grupo que os objetivos planejados haviam sido alcançados.

\section{O Contexto Da Escola 2}

A Escola Técnica Estadual (ETEC) em que essa experiência pedagógica foi realizada se localiza em um bairro da zona leste da cidade de São Paulo. Esta escola oferece Ensino Técnico Profissionalizante (Administração, Contabilidade e Informática) e EM regular.

Ingressam, em média, 120 estudantes no EM e são compostas três turmas que costumam se manter sem modificações até o final desse ciclo de escolarização.

Duas aulas de EF são ministradas para todos os anos do EM e ocorrem no mesmo período de aulas das demais disciplinas, uma vez que o professor de EF, para atender à proposta pedagógica da escola, deveria realizar um trabalho interdisciplinar e se envolver com os projetos escolares durante o ano letivo.

Ao iniciar como docente dessa unidade escolar em 2014, P2 realizou um diagnóstico com as duas turmas que lhe foram designadas (uma de $2^{\circ}$ ano e uma de $3^{\circ}$ ano).

Este diagnóstico iniciou com uma conversa na qual os estudantes relataram que as aulas de EF no Ensino Fundamental tinham caráter predominantemente recreativo, ou seja, os alunos praticavam os esportes que mais gostavam, e que suas experiências no EM nos anos anteriores foram compostas por treinamentos para participar de competições entre as escolas tomando parte apenas os estudantes que gostavam de jogar futebol ou vôlei. Os alunos que não participavam dessas atividades ficavam sentados observando os colegas ou fazendo atividades de outras disciplinas.

Após esse diagnóstico sobre a realidade da EF na escola, P2 começou a elaborar o seu planejamento tendo como principal objetivo estimular o pensamento crítico dos estudantes sobre as manifestações da cultura corporal com vistas a formar cidadãos críticos que pudessem se posicionar de forma efetiva sobre temas ligados às práticas corporais. 


\section{Enfatizar A Criticidade Por Meio De Projetos Com Vistas À Formação Cidadã}

P2 iniciou as aulas nessas duas turmas explicando aos estudantes o conceito de cultura corporal e a importância da compreensão das suas diferentes manifestações para que fizesse sentido a EF estar presente no EM, pois esse ciclo de escolarização possui como principal pilar a formação para a cidadania.

Em conjunto com as duas turmas, P2 escolheu estudar o esporte, o jogo e a ginástica no ano que se iniciava. Trazer uma proposta diferenciada para as aulas de EF é sempre um desafio, pois a maioria dos estudantes, como reflexo das ideias amplamente veiculadas na sociedade em que estão inseridos, tinham em mente que iriam para a quadra jogar futebol ou vôlei sem nenhuma intervenção do professor.

O livro Transformação Didático-Pedagógica do Esporte (KUNZ, 2006) foi utilizado como referência para o trabalho quando os esportes nas aulas de EF foram tematizados. Kunz (2006) defende que cada ser humano se-movimenta de acordo com a relação que estabelece com a cultura a partir de seu repertório, de sua história de vida, seus desejos e diversas experiências anteriores com as práticas corporais.

Com essa base teórica, ocorreram oportunidades para os alunos vivenciarem jogos que tinham relação com alguma modalidade esportiva e as condições da prática eram organizadas de maneira a permitir que todos pudessem participar.

Um dos jogos realizados foi o futebol-família, em que são organizados dois times, cada um deles forma um círculo de mãos dadas, se posiciona em uma das extremidades da quadra, e passa a bola entre os membros da equipe até conduzi-la ao o gol adversário, sem soltar as mãos. Ao chegar ao objetivo, um integrante do grupo tenta fazer o gol sem sair do círculo. Vence a equipe que primeiro fizer o gol.

Os estudantes também jogaram o voleibol de rede humana, composto por três times, sendo que um time faz o papel de rede enquanto os demais disputam o ponto. A equipe que deixar a bola cair no seu espaço passa a fazer o papel de rede e os jogadores que ocupavam esta posição passam a disputar o próximo ponto. Nesse jogo, de acordo com as experiências anteriores de cada turma, as regras oficiais do vôlei foram gradativamente inseridas.

Outra atividade realizada foi o goalball, sendo que, para esta prática, foram vendados os olhos dos estudantes e adaptado o espaço da quadra. Também foi realizada uma corrida com um dos estudantes vendado e o outro sem usar venda para simular as corridas do atletismo para pessoas com deficiência visual.

Em outra ocasião, P2 elaborou um jogo com regras parecidas com as do basquetebol para pessoas com deficiência física. Para isso, foram distribuídas cadeiras comuns pelo espaço da quadra e os estudantes disputavam o jogo de basquete sentados.

As atividades aqui descritas podem ser vistas como simples e comuns nas aulas de EF, no entanto, o seu diferencial reside nas rodas de conversa realizadas ao final de cada aula. Nesse momento, P2 explicava aos discentes que os jogos praticados não eram idênticos ao esporte de alto rendimento que assistiam na televisão, mas que tinham certa relação com eles por utilizarem fundamentos parecidos. Ainda era mencionado que, na escola, caso houvesse opção por realizar as práticas esportivas pautadas pelas regras oficiais, seria muito difícil que todos os estudantes conseguissem participar por conta dos diferentes níveis de habilidades existentes entre eles, pela falta de materiais e de espaço naquele ambiente escolar. Nesse momento da aula, os jovens podiam se posicionar sobre as suas experiências na realização desses jogos e refletiam em conjunto com P2 sobre as relações existentes entre essas atividades e o esporte propriamente dito.

Um dos instrumentos de avaliação utilizados definia que os estudantes criassem um jogo que utilizasse os fundamentos de alguma modalidade esportiva e que possibilitasse a 
participação de todos os alunos da turma. Uma vez criado, alguns desses jogos foram escolhidos pelos estudantes para serem realizados durante as aulas.

$\mathrm{Na}$ sala de aula houve reflexão conjunta sobre temas ligados à formação da cidadania dos jovens e, ao mesmo tempo, relacionados com as práticas esportivas. Tratou-se da relação do esporte com a saúde, com a mídia, conversou-se sobre casos de machismo, racismo e homofobia que acontecem no contexto das práticas corporais, sobre a violência nos estádios de futebol e sobre as questões econômicas que envolvem os esportes e os megaeventos esportivos.

Para tratar desses assuntos, P2 utilizou aulas expositivas, pesquisou reportagens que tratavam desses temas, debates em sala de aula e análise de documentários como, por exemplo, Dor e Lesão no Esporte, produzido pelo canal SporTv e Murderball: Paixão e Glória, um filme que mostra a vida de atletas com deficiência física.

Ao tratar desses temas, P2 utilizou como instrumentos de avaliação a criação de crônicas, charges e foi aplicada uma prova contendo perguntas dissertativas versando sobre os conteúdos desenvolvidos nas aulas.

Ao finalizar o estudo do bloco temático sobre os esportes, foi iniciado o estudo do bloco temático sobre a ginástica. O primeiro tema discutido foi a musculação. Foram realizadas aulas expositivas sobre os riscos e benefícios da realização de atividades de musculação por adolescentes, apontou-se a importância de um treinamento adequado para evitar problemas relacionados com o fechamento da epífise óssea e prejudicar o desenvolvimento corporal normal e, com isso, acarretar problemas ao crescimento (CAMPOS, 2004).

Na sala de aula foi realizada uma breve exposição sobre o sistema musculoesquelético, comentando a importância da prática dos exercícios resistidos para pessoas que possuem doenças crônicas, foram explicadas as diferenças entre anabolizantes e suplementos alimentares e foi feito um amplo debate sobre os riscos da utilização de anabolizantes, principalmente pelos jovens.

Nas aulas práticas, P2 ensinou a realizar exercícios para os membros superiores, membros inferiores e tronco com a utilização de colchonetes e halteres, porque a escola contava com esses materiais. Nestas aulas, após observarem a demonstração da técnica de diferentes exercícios, os estudantes realizavam o exercício em duplas e eram corrigidos caso executassem algum exercício com a técnica inadequada.

Para finalizar as discussões sobre musculação, P2 conversou sobre as diferenças entre alongamento e aquecimento, principalmente para desmistificar os mitos que são muito enfatizados pelo senso comum sobre o alongamento, tendo como referência Camara et al. (2015).

O trabalho de Ginástica Geral foi realizado a partir da proposta de Zotovici (2007). Além disso, foram vivenciados alguns fundamentos da Ginástica Artística e, durante o estudo da Ginástica Rítmica, foram elaborados materiais alternativos para sua prática. No interior deste bloco temático, foram realizadas algumas atividades relacionadas à Ginástica Acrobática.

Em sala de aula, assistiu-se a vídeos com coreografias oficiais das três modalidades ginásticas competitivas e, também, apresentações de Ginástica Geral. Após esse momento, em conjunto com os estudantes organizados em grupos, $\mathrm{P} 2$ e alunos passaram a elaborar apresentações de Ginástica Geral, tendo como regra utilizar ao menos dois aparelhos da Ginástica Rítmica, dois fundamentos da Ginástica Artística e um posicionamento da Ginástica Acrobática. Essa coreografia teria duração máxima de dois minutos e deveria expressar, corporalmente, um tema de importância para a sociedade.

Após um mês de ensaios, os estudantes criaram coreografias que expressavam o machismo, o racismo, a homofobia, a desigualdade social, a religião, a luta dos indígenas para manter as suas terras, e a ditadura militar. 
Suas apresentações foram filmadas e as filmagens mostradas a eles. Esse momento proporcionou a oportunidade de realizar diferentes debates sobre os temas que surgiram durante as aulas, considerando-se que um dos principais objetivos educativos era que a EF estimulasse o desenvolvimento do pensamento crítico e a formação da cidadania destes alunos.

\section{Considerações Finais}

Existe espaço para a EF no Ensino Médio? Os relatos de experiência aqui apresentados mostram que sim, uma vez que em ambos objetivou-se desenvolver o pensamento crítico dos alunos, o qual lhes permita tomar decisões em prol da cidadania democrática e responsável, dar voz ao jovem ao fazê-lo copartícipe das ações pedagógicas desde o planejamento até a avaliação e trabalhar com conteúdos que despertem sua curiosidade, interesse e que são significativos para suas vidas.

Vislumbramos um dia em que a presença da EF nas escolas seja vista como uma ferramenta indispensável na promoção do direito de aprendizagem e de desenvolvimento integral do estudante e, desse modo, conquiste legitimidade social, muito mais importante, a nosso ver, do que a legalidade que garante sua obrigatoriedade.

A conquista da legitimidade da EF escolar pode ocorrer quando os docentes de EF efetivarem práticas pedagógicas interdisciplinares por meio de projetos significativos, nos quais os conhecimentos sejam trabalhados de maneira integrada e que respondam a questões colocadas pelos próprios estudantes, mediados pela orientação didática do professor. Nesse sentido, é um imperativo pedagógico superar o mecanicismo da prática pela prática, a oferta de conteúdos repetitivos, antiquados e que não mais fazem sentido aos jovens, superar a oferta de conteúdos desvinculados das questões que eles enfrentam no cotidiano, superar a cobrança de um tipo de rendimento diferente daquele que todo estudante pode constatar em si mesmo e no grupo com o qual convive.

Os docentes, de uma maneira geral, precisam encontrar mecanismos para se organizarem, para debater, para se fazerem ouvir e representar para que Medidas Provisórias ditadas pelo governo deixem de ser impingidas sobre a educação brasileira.

Possíveis impactos e consequências da MP n ${ }^{\circ} 746 / 2016$, que faz ressurgir o destaque à educação técnica com o estímulo subjacente à terminalidade da escolarização no EM, em geral afeta a camada mais pobre da população e não garante espaço para o desenvolvimento do espírito crítico, participativo e cidadão.

A MP $n^{0} 746 / 2016$ agrava a situação da educação no país quando cria condições que permitem que docentes com "notório saber" atuem na Educação Básica sem nenhum tipo de formação pedagógica, quando afirma defender uma educação integral para o EM sem aumentar os recursos disponíveis para a educação e retira a obrigatoriedade de disciplinas como Sociologia e Filosofia desse nível de ensino. Tais condições parecem repetir cenas do passado ao oferecer melhores condições para que a parcela da população que não apresenta urgência em se inserir no mercado de trabalho seja privilegiada com maiores possibilidades de ingressar no Ensino Superior, se preparar para exercer profissões com melhor remuneração e assumir postos de comando na sociedade.

O professor de EF, que faz parte de um cotidiano escolar complexo, repleto de políticas públicas com interesses subjacentes, conflitantes, às vezes ilegítimos para a maioria da sociedade, precisa ver-se como um elemento que pode interferir nesse sistema. Para isso, é preciso ter convicção de que a atuação docente pode ajudar a desconfigurar uma tradição didático-pedagógica anacrônica, tecnicista e que não possui mais relação com a função social e democrática da escola contemporânea.

Talvez, dessa forma, seja possível legitimar a EF como uma área de conhecimento que traz conteúdos e vivências importantes para a formação da cidadania dos jovens, independen- 
temente de constar como componente curricular obrigatório na legislação e nos documentos oficiais. Dessa maneira, inverteremos a atual lógica do jogo.

\section{Referências}

BOSSLE, F.; BOSSLE, C. B.; NEIRA, M. G. Desafios para a docência na Educação Física Escolar. In: BOSSLE, F.; WITTIZORECKI, E. S. Didáticas da Educação Física: formação docente e cotidiano escolar. Curitiba, PR: CRV, 2016. p. 119-132.

CAMARA, F. M. et al. O mandamento do alongamento: evidências e propostas para reflexão. Revista Brasileira de Ciência e Movimento, v. 23, n. 2, p. 148-155, 2015.

CAMPOS, M. A. Musculação: diabéticos, osteoporóticos, idosos, crianças, obesos. 2. ed. Rio de Janeiro: Sprint, 2004.

CORREIA, W. R. Educação Física no Ensino Médio: questões impertinentes. 2. ed. Várzea Paulista, SP: Fontoura, 2011.

DEWEY, J. Democracia e educação: introdução à filosofia da educação. São Paulo: Companhia Editora Nacional, 1959.

1978.

Vida e Educação. 10. ed. São Paulo: Melhoramentos - Ministério da Educação,

. A escola e a sociedade. A criança e o currículo. Lisboa: Relógio D’Água, 2002.

GONZÁlEZ, F. J.; FRAGA, A. B. Afazeres da Educação Física na escola: planejar, ensinar, partilhar. Erechim, RS: Edelbra, 2012.

HERNÁNDEZ, F.; VENTURA, M. A organização do currículo por projetos de trabalho: o conhecimento é um caleidoscópio. 5. ed. Porto Alegre: Artes Médicas, 1998.

KILPATRICK, W. R. Educação para uma civilização em mudança. 12. ed. São Paulo: Melhoramentos, 1974.

KUNZ, E. Transformação Didático-Pedagógica do Esporte. 7. ed. Ijuí, RS: Unijuí, 2006.

NOGUEIRA, V. A. O Planejamento Participativo na Educação Física Escolar: relatando a construção de Projetos. In: Seminário de Metodologia de Educação Física, VI, 2016, São Paulo. Anais... São Paulo: FEUSP, 2016.

ZOTOVICI, S. A ginástica geral como prática pedagógica na Educação Física Escolar. In: SCARPATO, M. Educação Física: como planejar as aulas na Educação Básica. São Paulo: Avercamp, 2007. p. 141-156. 
Endereço para correspondência:

danieltmaldonado@yahoo.com.br

Daniel Teixeira Maldonado

Instituto Federal de Educação, Ciência e Tecnologia

R. Pedro Vicente, 625

Canindé, São Paulo - SP, 01109-010 